\title{
An Attempt to Assess Recovery/Recrystallization Kinetics in Tungsten at High Temperature Using Statistical Nanoindentation Analysis
}

\author{
Liz Karanja ${ }^{1}$, Matthieu Lenci ${ }^{1}$, David Piot ${ }^{1}$, Claire Maurice ${ }^{1}$, Alan Durif ${ }^{2}$, Marianne Richou ${ }^{2}$, Laurent Gallais ${ }^{3}$, \\ Marco Minissale ${ }^{4}$ and Guillaume Kermouche ${ }^{1, *}$ \\ 1 Mines Saint-Etienne, CNRS, UMR 5307 LGF, Centre SMS, F-42023 Saint-Etienne, France; \\ liz.karanja@mines-albi.fr (L.K.); lenci@emse.fr (M.L.); piot@emse.fr (D.P.); maurice@emse.fr (C.M.) \\ 2 CEA, IRFM, F-13108 Saint-Paul-Lez-Durance, France; Alan.DURIF@cea.fr (A.D.); \\ Marianne.RICHOU@cea.fr (M.R.) \\ 3 Centrale Marseille, Institut Fresnel, Aix Marseille University, CNRS, 13007 Marseille, France; \\ laurent.gallais@fresnel.fr \\ 4 Aix Marseille University, CNRS, PIIM, 13007 Marseille, France; marco.minissale@univ-amu.fr \\ * Correspondence: kermouche@emse.fr
}

\section{check for}

updates

Citation: Karanja, L.; Lenci, M.; Piot, D.; Maurice, C.; Durif, A.; Richou, M.; Gallais, L.; Minissale, M.; Kermouche, G. An Attempt to Assess Recovery/Recrystallization Kinetics in Tungsten at High Temperature Using Statistical Nanoindentation Analysis. Crystals 2021, 11, 37. https://doi.org/10.3390/ cryst11010037

Received: 30 November 2020 Accepted: 27 December 2020 Published: 31 December 2020

Publisher's Note: MDPI stays neutral with regard to jurisdictional clai$\mathrm{ms}$ in published maps and institutional affiliations.

Copyright: (C) 2020 by the authors. Licensee MDPI, Basel, Switzerland. This article is an open access article distributed under the terms and conditions of the Creative Commons Attribution (CC BY) license (https:// creativecommons.org/licenses/by/ $4.0 /)$.
Abstract: Measurement of recovery and recrystallization kinetics of tungsten at high temperature is a key issue for many applications, such as plasma facing units in the framework of thermonuclear fusion. These kinetics are mostly derived from Vickers hardness and EBSD measurements, which can lead to some inaccuracies due to the competition between recovery and recrystallization mechanisms. A complementary/alternative approach based on statistical grid nanoindentation is proposed in this paper. The basic idea is to assume that the fraction recrystallized can be deduced using the hardness probability density function measured on a fully recrystallized sample. The hardness probability density function of the set of non-recrystallized grains can then be analyzed. The methodology was applied to rolled tungsten samples annealed at high temperature. It was clearly observed that recovery and recrystallization overlapped in terms of softening fraction in the investigated timetemperature range. Activation energy of the static recovery mechanism is in the correct order of magnitude compared to bulk self-diffusion in tungsten. High-throughput nanoindentation analysis appears as a promising way to investigate recrystallization/recovery mechanisms in metals.

Keywords: recrystallization; recovery; annealing; hardness; tungsten; statistical analysis

\section{Introduction}

Thermonuclear fusion is a one non-carbon emitting promising source of energy, but remains one of the most challenging, as plasma has to be confined magnetically. Any imperfections can lead to high heat fluxes over the main wall [1]. Pure tungsten grades have proved their ability to resist to such high heat fluxes. Nevertheless, repeated thermal cycles at high temperatures (up to $1800^{\circ} \mathrm{C}$ ) can lead to a detrimental loss of mechanical properties [2] due to the thermally activated restoration process known as primary recrystallization [3]. First, the ductile to brittle transition temperature (DBTT) of tungsten is shifted to higher temperatures (embrittlement issues). Second, the yield stress is lowered, which promotes plastic flow during thermal fatigue cycles. A drastic reduction of the number of cycles to failure is observed. The development of methodologies to measure/predict recrystallization kinetics of tungsten is therefore of primary importance for thermonuclear fusion [4]. Similar issues are encountered in any applications involving high heat flux (high temperature furnaces, lighting, thin film deposition, turbines, etc.).

The rate of recrystallization is affected by the annealing temperature and the initial strain-i.e., initial microstructural state-that is a direct consequence of processing. The recrystallization temperature of pure tungsten for $3600 \mathrm{~s}$ annealing has been reported to be 
in the range $1100-1500{ }^{\circ} \mathrm{C}[2,4,5]$. It is necessary to measure the recrystallization kinetics in a temperature range closer to thermonuclear fusion applications though, which can only be done using a specific annealing set-up [6,7]. Nevertheless, this type of device can only process one sample at a time. The number of samples to investigate the recrystallization kinetics at a given temperature is therefore limited. The latter is mostly measured through the recrystallization-induced softening using post-mortem hardness tests. However, primary recrystallization competes with static recovery, a thermally-activated restoration process that is also driven by the stored energy of the deformed state. That makes it difficult to discriminate those two mechanisms with hardness tests [3]. The hardness test remains an overall measurement of sample mechanical properties. To overcome such an issue, electron back-scatter diffraction (EBSD) is often employed to separate former grains that soften through static recovery from recrystallized grains [8,9]. The orientation distribution within a grain is used to segment the recrystallized grain through the use of suitable metrics $[10,11]$.

An alternative mechanical approach would be to independently probe each grain of a microstructure to determine whether it is recrystallized or recovered. Such measurements are offered by nanoindentation testing, which permits one to measure mechanical properties over a volume of a few $\mu \mathrm{m}^{3}$ or even less [12,13]. Zayachuk et al. [14] clearly highlighted that nanoindentation helped to discriminate whether a tungsten grain is recrystallized or not. Hardness and pile-up heights are shown to be lower in recrystallized grains than in deformed ones. Such individual measurements are, however, time-consuming and poorly selective when determining whether a fraction is recrystallized. The statistical nanoindentation theory that replaces the analysis of individual indents with the analysis of a large set of indents might overcome this issue. It has been successfully used to measure fractions of phases in materials [15]. The main assumption is that hardness distribution of a given phase does not overlap hardness distributions of the others [16]. The variance of hardness distribution of a given phase is related to the self phase heterogeneity, i.e., crystal orientation, dislocation density, defects, etc. In this paper it is proposed to examine whether or not this kind of measurement can be done to measure the recrystallized or recovered fractions of rolled tungsten samples.

The first part of this paper deals with the adaptation of statistical nanoindentation theory to the measurement of fraction recrystallized and recovery parameters. The different set-ups used are then described. More precisely, two tungsten materials with different initial microstructures are compared. Results are presented in terms of hardness distribution versus annealing time and temperature. They are then post-treated to extract the fraction recrystallized and the mean hardness of the remaining recovered structure. These results are then discussed to highlight the advantages and also the limits of the new methodology to investigate recrystallization/recovery phenomena at high temperatures.

\section{Theory}

\subsection{Recrystallization/Recovery}

Recovery and recrystallization are thermally-activated restoration processes in which microstructural defects may be removed or alternatively arranged in configuration of lower energy. Recrystallization lies at the nucleation and growth sites of dislocationfree grains within the deformed or recovered structures [3]. Recrystallization is fully achieved when old grains are consumed, which results in an new microstructure with a low dislocation density. The extent of recrystallization is often described by $X-$ i.e., the fraction recrystallized. The recrystallization kinetics during isothermal annealing are typical of many transformation reactions based on consistent nucleation and growth processes. They are usually described using the JMAK equation.

$$
X=1-\exp \left(-B t^{n}\right)
$$

where $t$ is the annealing time, $n$ is the Avrami exponent and $B$ is a parameter that depends on nucleation and grain growth rates, i.e., the rate of recrystallization. It is affected by 
the annealing temperature and the initial strain-i.e., stored energy. The latter makes recrystallization strongly dependent upon the initial microstructural state that is a direct consequence of prior thermomechanical processing. Recrystallization kinetics can be measured through the loss of mechanical properties after isothermal annealing treatments. Neglecting recovery-induced restoration, the fraction recrystallized equals the softening fraction $X_{H}$ measured through conventional hardness measurements:

$$
X_{H}=\frac{H_{\text {init }}-H}{H_{\text {init }}-H_{r x}}
$$

where $H, H_{\text {init }}$ and $H_{r x}$ are respectively the hardness after annealing at a given time and temperature, the hardness of the deformed material (initial state) and the hardness of the fully recrystallized material.

However, in the presence of recovery, such an equation cannot be used in state. Recovery often refers to microstructural changes occurring prior to recrystallization and which partially restore the mechanical properties to their values before deformation. Like recrystallization, recovery is driven by the stored energy of the deformed state, and they are thus competing processes. On one hand the extent of recovery depends on the ease with which recrystallization occurs [3]. On the other hand, a significant amount of prior recovery may in turn influence the recrystallization kinetics. Many theories have been built to model recovery of mechanical properties during annealing $[17,18]$. Considering that recovery is controlled by thermally activated glide or cross-slip [19], the Kuhlmann's theory [3] yields a logarithmic decrease of hardness with time that is in good agreement with experimental data. This methodology is very efficient when the hardness loss due to recovery is of a measurable magnitude compared to the hardness loss due to recrystallization. Moreover, it is required that most of hardness loss due to recovery occurs before the onset of recrystallization. This approach is very suitable to highly deformed materials annealed at quite low temperatures, for which recovery mechanisms start rapidly and recrystallization mechanisms are delayed. It has been used with success to investigate recovery and recrystallization mechanisms in rolled thin tungsten plates by Ciucani et al. [20]. When recrystallization and recovery overlap, it is necessary to use more advanced models [21] to separate their contributions to the strength change that takes place during annealing. Statistical nanoindentation analysis that lies in hardness measurements at the grain scale can therefore appear as an interesting alternative to separate these two contributions.

\subsection{Statistical Nanoindentation Theory}

Most of the continuum indentation analyses on homogeneous materials are based on the self-similarity approach [22,23]. The indentation solutions have no length scale limit and assume spatially uniform mechanical properties; thus the indentation properties extracted are average quantities characteristic of material length scales. In the framework of composite materials with phases of different mechanical properties, if the indentation depth is smaller than the phases present, an indentation test can access the different material properties of each phase [15]. A large number of indentations are made by satisfying the condition that grid spacing between the indents is greater than the indentation depth and much larger than the characteristic phase size, which ensures that there is no statistical bias with respect to the spatial distribution of the two phases [16,24]. The results from the large massive tests can be analyzed using elementary statistics assuming Gaussian distributions to describe phase hardness:

$$
p_{i}(H)=\frac{1}{S_{i} \sqrt{2 \pi}} \exp \left(-\frac{1}{2}\left(\frac{H-H_{i}}{S_{i}}\right)^{2}\right)
$$

where $H_{i}$ is the mean hardness and $S_{i}$ is the standard deviation of the $i$ th phase. The fraction of phase $f_{i}$ is deduced from the probability density function assuming that $p(H)=\sum_{i=1}^{n} f_{i} p_{i}(H)$ and $\sum_{i=1}^{n} f_{i}=1$ where $n$ is the number of phases. Such a decon- 
volution technique requires that hardness distributions related to the different phases do not overlap [16].

In the recrystallized state it may be assumed that the mechanical properties in a material are mainly due to crystallographic orientations and point defects [14]. With hardness being crystal orientation-dependent, it is proposed here to consider that the hardness probability density function of the fully recrystallized state can be described using a Gaussian function:

$$
p_{r x}(H)=\frac{1}{S_{r x} \sqrt{2} \pi} \exp \left(-\frac{1}{2}\left(\frac{H-H_{r x}}{S_{r x}}\right)^{2}\right)
$$

$H_{r x}$ is the mean hardness of the fully recrystallized state and $S_{r x}$ is the corresponding standard deviation.

Upon annealing the deformed structure at an elevated temperature, the microstructure and mechanical properties are partially restored to their original values corresponding to the above recrystallized state. The microstructure is therefore composed of recrystallized and recovered grains. The resulting hardness distribution is a signature of the mechanical properties of these two sets of grains. Consequently, the hardness distribution $p_{\text {Int }}$ can be written as:

$$
p_{\text {Int }}(H)=\zeta p_{r x}(H)+p^{*}(H)
$$

whereby $\zeta$ is a constant. The function $p^{*}(H)$ is related to the probability density function of the set of recovered grains. The recrystallization fraction is then related to $p^{*}(H)$ through $X=1-\int_{0}^{+\infty} p^{*}(H) d H$. The recovered grains' hardness distribution is thus given by $p_{\text {rec }}=p^{*} /(1-X) \cdot p^{*}(H)$ can be computed through the minimization of a suitable cost function, such as the one proposed in Equation (6).

$$
\underset{\zeta}{\operatorname{argmin}} \int_{0}^{+\infty}\left|p^{*}(H)\right| d H
$$

Let us note that it is the first attempt to calculate the fraction recrystallized from statistical nanoindentation data. This approach is likely too simplistic and might suffer from some flaws. For instance, a spurious tail of the recovered grains' hardness distribution can be observed sometimes for hardness values lower than the mean hardness of the recrystallized materials. The hardness distribution of the recrystallized grains can sometimes significantly overlap with the hardness distributions of recovered grains, especially when the extent of recovery is quite high. In that case it is supposed that recrystallization prevails to recovery. It has been chosen here to clean-up these artefacts, i.e., $p^{*}(H)=0$ for $H<H_{r x}$, once the minimization process is successful.

\section{Materials and Methods}

Samples were extracted from the middle of a tungsten plate of commercial purity complying with ITER specifications. They were annealed through a laser heating system described in Ref [7]. This device allows the annealing of samples at up to $3000{ }^{\circ} \mathrm{C}$, with fast heating rates. Samples were annealed at different temperatures in the range 1450 to $1600{ }^{\circ} \mathrm{C}$ for different annealing times (from 50 to $3600 \mathrm{~s}$ ). The heating rate was set to $200^{\circ} \mathrm{C} / \mathrm{s}$ so that the time to reach $1600{ }^{\circ} \mathrm{C}$ was $8 \mathrm{~s}$. At such a rate the heating time may be neglected in the estimation of the annealing time. The fully recrystallized state was achieved using an annealing treatment at $1800{ }^{\circ} \mathrm{C}$ during $600 \mathrm{~s}$. Only one sample per annealing treatment was available for statistical nanoindentation analysis.

Nano-indentation grids $(13 \times 13)$ were used with a nanoindenter XP $($ Keysight Technologies, Santa Rosa, CA, USA) with a Berkovich diamond tip. The indentation set-up was load-controlled with a maximum force of $450 \mathrm{mN}$. Samples were mounted and polished using abrasive grits of decreasing sizes down to a final polishing step using a $1 \mu \mathrm{m}$ diamond solution. The load was applied using the dynamic method known as continu- 
ous stiffness measurement (CSM) to continuously measure hardness versus penetration depth [12]. The indenter was calibrated using a standard fused silica specimen. Hardness $H$ was computed using the Loubet's method [13]. Average hardness was extracted over a penetration depth range that avoids indentation size effect issues [25]. The space between indents was set to $50 \mu \mathrm{m}$ along $\mathrm{x}$ and $\mathrm{y}$ axes, as shown in Figure 1. An average of the two grids performed for a given sample was used to determine the probability density function. These distributions were derived from histograms computed with 13 bins, i.e., square root of the number of data points. Each bin width was chosen according to the difference between hardness minimum and maximum values. It is worth noting that some indents may be located near grain boundaries, resulting in an artificially higher hardness than in the grain core. In such a case, the self-similarity of the indentation test is not respected. These indents were identified a posteriori and were not considered in the further statistical nanoindentation analysis [15].

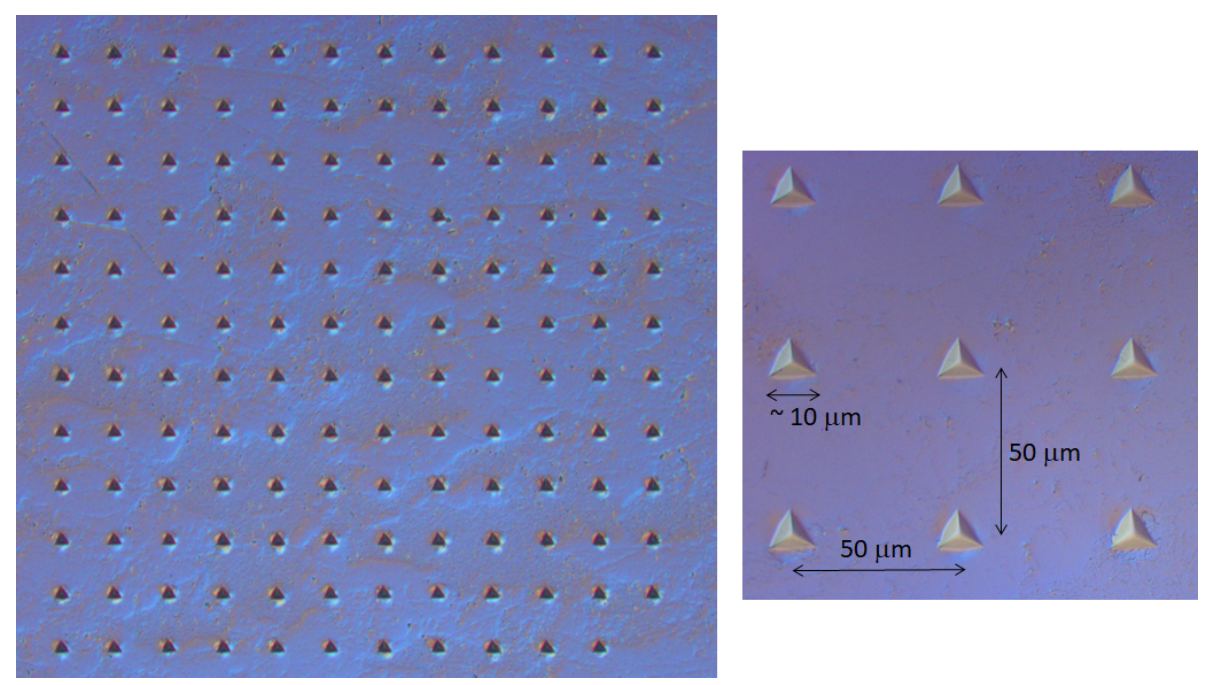

Figure 1. Nanoindentation grids. The space between indents was set to $50 \mu \mathrm{m}$. The print size was about 5-10 $\mu \mathrm{m}$.

Microstructural analyses were performed using electron back-scattering diffraction (EBSD) in a scanning electron microscope (JEOL FEG 6500F). EBSD data were processed using the MATLAB toolbox MTEX [26]. A grain was considered as a region surrounded by high angle boundaries greater than $15^{\circ}$. The low angle boundaries were set as $2-15^{\circ}[2,6]$. Subgrains within a grain and intragrain misorientation are the signature of the stored energy due to the prior deformation process. The orientation distribution within a grain can be used to segment the recrystallized grain through the use of suitable metrics, such as the grain orientation spread (GOS) [10,11]. It is proposed here to use the GOS approach with a threshold value of $2^{\circ}$ to separate the recrystallized grains from the unrecrystallized ones [27]. It is worth noting that quantifying accurately the fraction recrystallized using EBSD measurements is still a matter of debate [28].

\section{Results and Discussion}

Initial state and fully recrystallized state hardness probability density functions are plotted in Figure 2. Initial state mean hardness $H_{\text {init }}$ was about 5.4 GPa with a standard deviation of $0.25 \mathrm{GPa}$, whereas fully recrystallized state mean hardness $H_{r x}$ was about 4.6 GPa with a standard deviation of $0.2 \mathrm{GPa}$. A small overlap between the two probability density functions may be pointed out, which means that the fraction recrystallized was likely non-zero for the initial state. It was actually estimated to be about $2-3 \%$. On the contrary, the solution of the softening fraction through Equation (2) is obviously zero. The fully recrystallized state hardness distribution was fitted using the Gaussian function described in Equation (4). A small deviation with a perfect Gaussian function is observable, 
which would lead to estimating a fraction recrystallized lower than $100 \%$ from Equation (6). It was actually estimated to be about $90 \%$. Consequently, a fraction recrystallized lower than 3\% (resp higher than $90 \%$ ) is not considered hereafter.

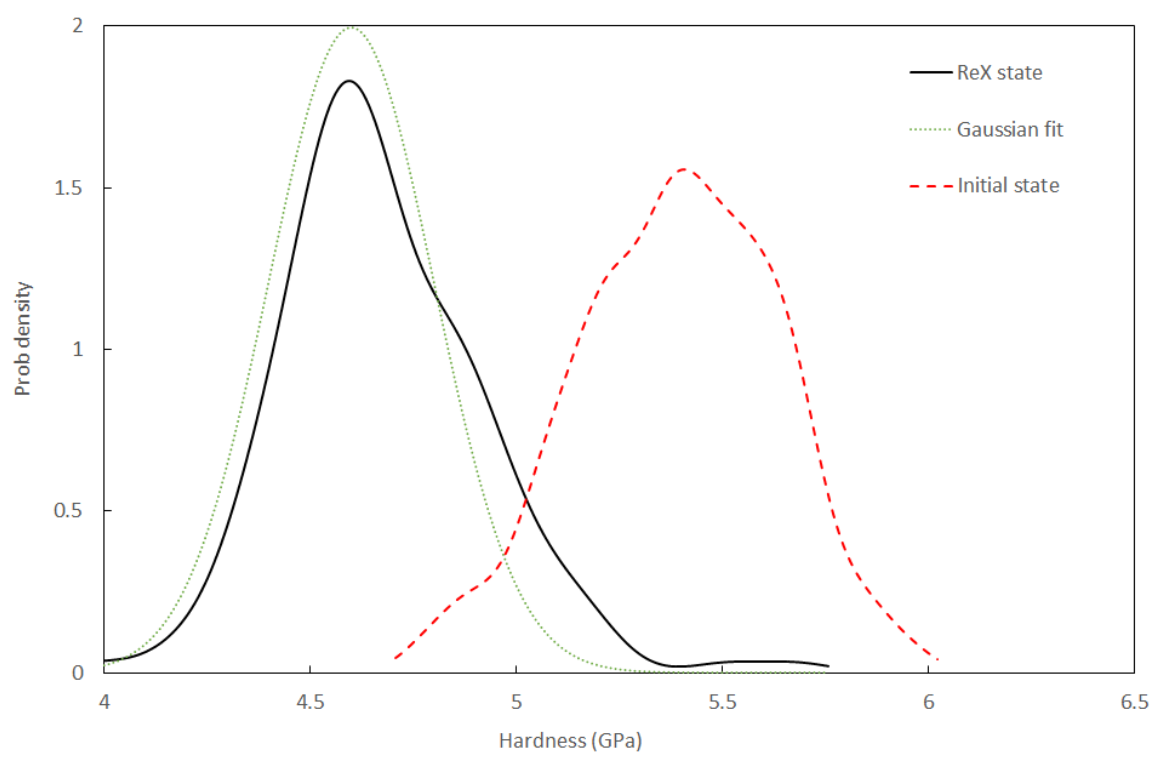

Figure 2. Comparison of the hardness probability density function for the initial state and the fully recrystallized $(\operatorname{ReX})$ state. The ReX state was fitted using a Gaussian function.

Effects of annealing time and temperature on hardness distribution are shown in Figure 3. The curves are shifted significantly to the left for increasing annealing time and/or temperature. The frequency distribution tends to have a higher standard deviation and thus wider distribution plots compared to the fully recrystallized plots. However, the set of data is clearly not rich enough regarding microstructure heterogeneity to permit a quantitative analysis of the upper distribution tail. Therefore, results will be mostly analyzed hereafter from the mean values of the measured distributions. In that sense, the mean hardness is used to compute the softening fraction $X_{H}$ using Equation (2). Let us recall here that the softening fraction differs from the fraction recrystallized, since the recovery-induced softening is accounted for.
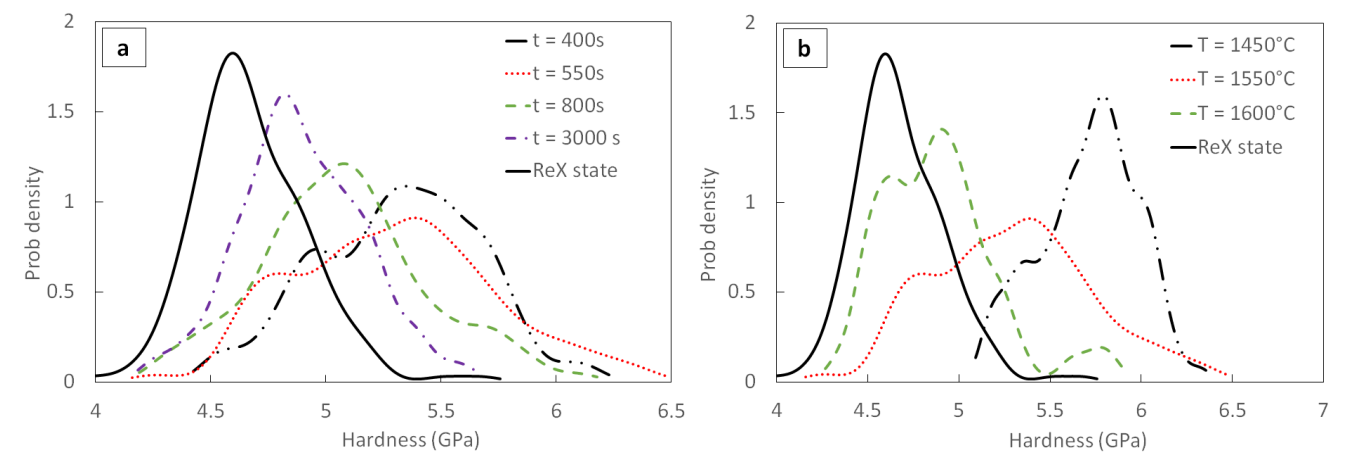

Figure 3. Hardness distributions after annealing. (a) The effect of the annealing time $\left(\mathrm{T}=1550{ }^{\circ} \mathrm{C}\right)$. (b) The effect of the annealing temperature $(t \approx 500 \mathrm{~s})$.

Figure 4 shows the hardness standard deviation versus the softening fraction. The standard deviation is maximum when the softening fraction approaches $50 \%$ and is minimum both for the initial state and the fully recrystallized state. It is worth noting that the trend is the same whatever the annealing temperature. The standard deviation reflects somehow the microstructure heterogeneity. Consequently hardness standard deviation may appear 
as a signature of recrystallization/recovery mechanisms [29]. However, the variation remains too low to make it useful for a quantification purpose.

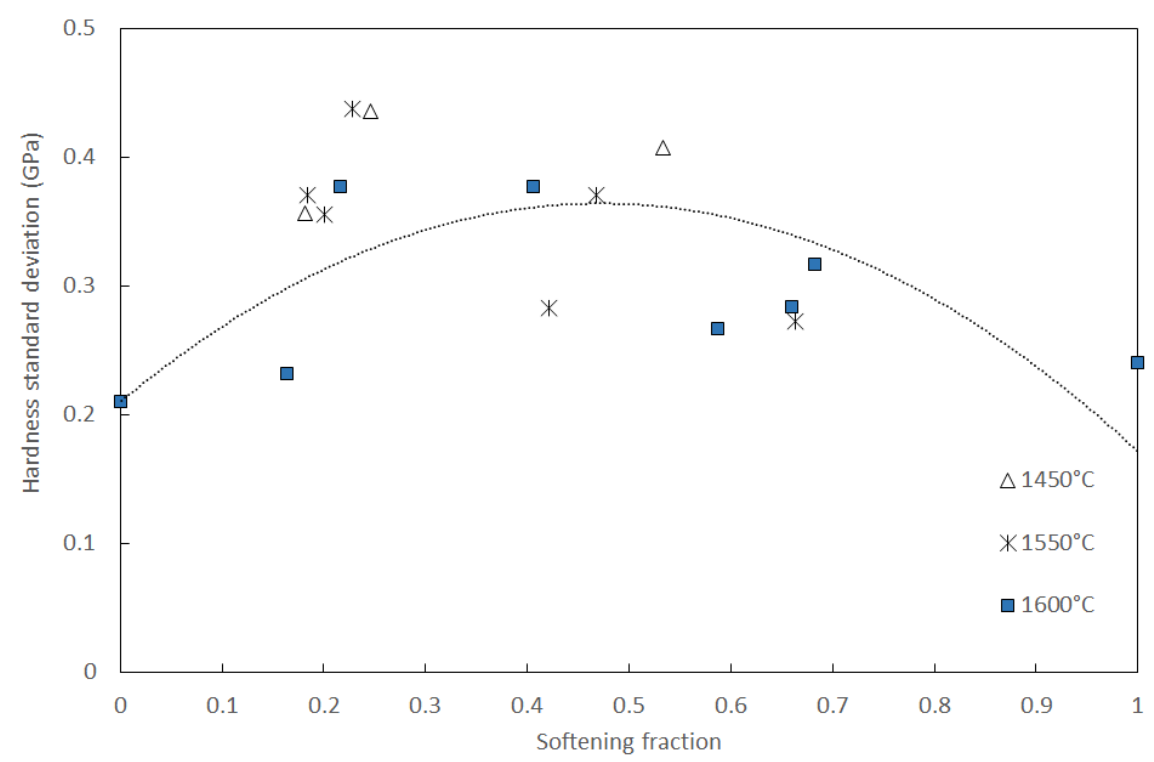

Figure 4. Hardness standard deviation versus softening fraction. The standard deviation is maximum when the softening fraction approaches $50 \%$.

The measurement of the fraction recrystallized from statistical nanoindentation analysis lies in the quantification of the contribution of recrystallized grains to the hardness probability density function. It is first required to determine the probability density function of the fully recrystallized state as illustrated in Figure 2. The fraction recrystallized and hardness probability density function $p_{\text {rec }}$ of recovered grains are yielded by the minimization of the cost function (6), as shown in Figure 5.

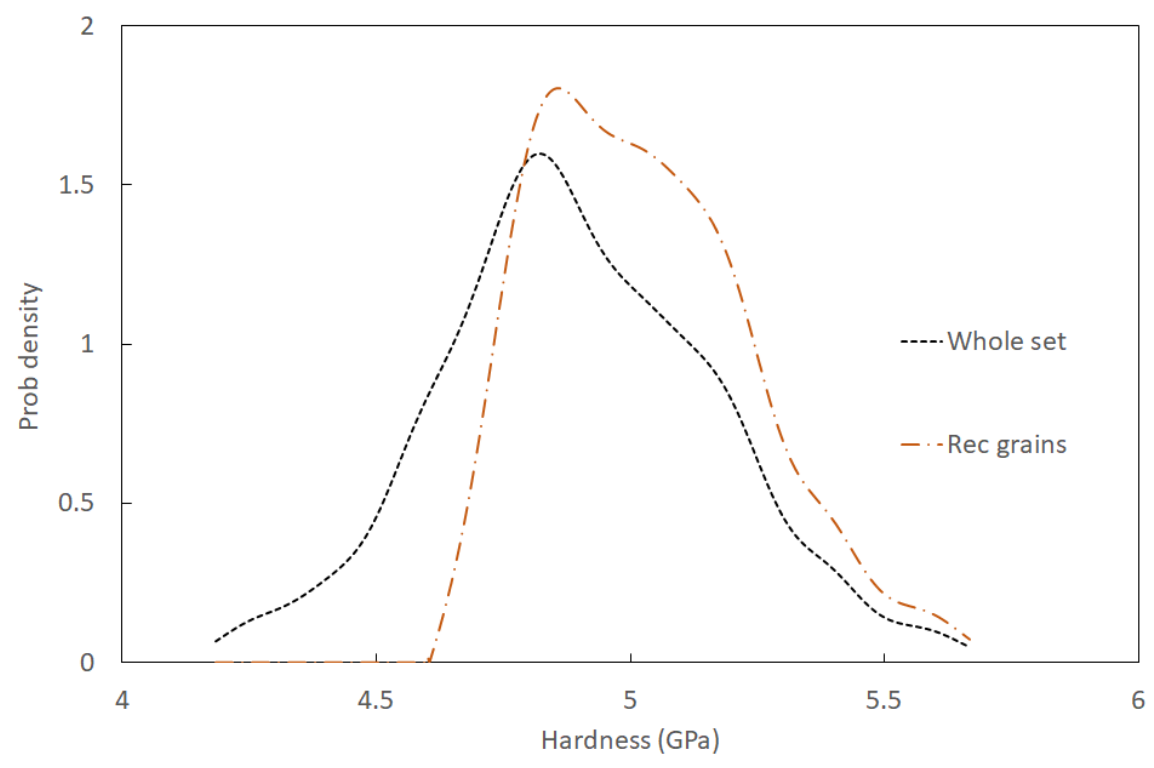

Figure 5. Hardness probability density function of recovered grains compared to the full probability density function $\left(\mathrm{T}=1550{ }^{\circ} \mathrm{C}, \mathrm{t}=3000 \mathrm{~s}\right)$. Softening fraction $X_{H}$ is about $65 \%$ here, whereas fraction recrystallized $X$ computed through nanoindentation testing is about $30 \%$.

The softening fraction is about $65 \%$ here, whereas the fraction recrystallized computed through nanoindentation testing is about $35 \%$. It is worth noting that the fraction recrystal- 
lized measured from EBSD lays in-between $(\approx 50 \%)$. This difference with nanoindentation is not surprising since it is strongly dependent upon the criterion chosen to detect a recrystallized grain. For instance, Figure 6 illustrates the microstructural evolution observed through EBSD measurements for increasing annealing time (increasing softening fraction) at $\mathrm{T}=1550{ }^{\circ} \mathrm{C}$. Recrystallized grains are colored regarding their orientations. Uncolored grains are unrecrystallized grains.
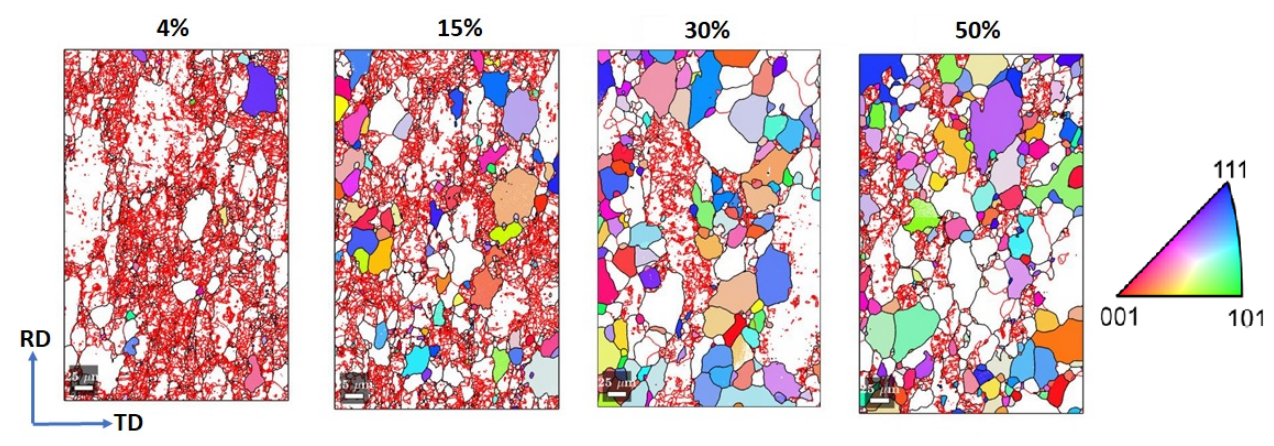

Figure 6. EBSD maps representing the evolution of softening fraction at $\mathrm{T}=1550{ }^{\circ} \mathrm{C}$. The grain boundaries are in black, the sub-grain boundaries are in red and the recrystallized grains are colored according to (IPF Z-normal direction).

The time-evolution of the fraction recrystallized $\left(\mathrm{T}=1550{ }^{\circ} \mathrm{C}\right)$ computed using the procedure above and from EBSD measurements is compared to the softening fraction (Figure 7). The mean hardness has the same meaning as a Vickers test for which the hardness is an average value over several grains due to the indentation size [6]. More precisely, it is a mixed value of the hardness of recovered grains and recrystallized grains, and what is computed is much more a restoration-induced softening fraction than a fraction recrystallized. Methodologies based only on Vickers macro-hardness tests usually overestimate the fraction recrystallized by neglecting the effect of recovery. Therefore, it is expected that the softening fraction will be higher than the true fraction recrystallized. The softening fraction is here up to two times larger than the fraction recrystallized estimated through the statistical nanoindentation analysis. This latter permits one to separate the contributions of recovery and recrystallization mechanisms to macroscopic softening. It is not surprising that EBSD measurements lead to in-between values, since statistical nanoindentation and EBSD methods are both based on measurements at the grain-scale. Nonetheless, the fraction recrystallized estimated from EBSD depends strongly on the chosen criterion to detect a recrystallized grain. Clearly a universal definition of the measurement of recrystallization fraction through EBSD measurement is a matter of debate [28,30] and is far beyond the scope of this paper.

Once the fraction recrystallized is estimated, the hardness probability density function restricted to the set of recovered grains $p_{\text {rec }}$ (Figure 5) can be analyzed. The time-evolution of the mean value of hardness $\left(\mathrm{T}=1550{ }^{\circ} \mathrm{C}\right)$ is plotted in Figure 8 . As expected, it decreases with time and is above the mean hardness computed on the whole set. However, the trends-i.e., the slopes-are very similar for the two sets of grains. The contribution of the recrystallization mechanism to the hardness decrease is quite low-about $0.1 \mathrm{GPa}-$ whereas the contribution of the recovery mechanism is about $0.4 \mathrm{GPa}$. For the temperature range investigated in this paper-i.e., $1450-1600{ }^{\circ} \mathrm{C}$-recovery seems to prevail in terms of softening. To get similar conclusions without using statistical nanoindentation analysis would require one to correlate EBSD measurements with Vickers measurements. However, a limitation of the present analysis deserves to be discussed here. The hardness probability density function of the fully recrystallized state has been measured on one sample, the only one that was available during the period of time of this investigation. If the nanoindentation-derived fraction recrystallized were to be underestimated, the recoveryinduced hardness drop would be overestimated. At least, it may be concluded that recovery 
and recrystallization mechanisms overlap and that recovery has to be considered to accurately measure recrystallization kinetics of tungsten at elevated temperature.

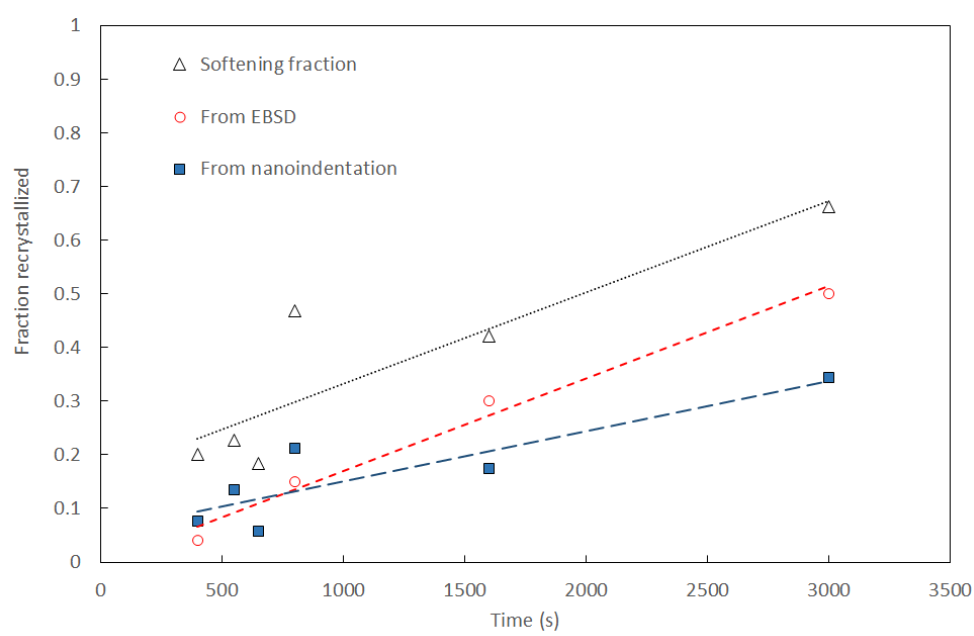

Figure 7. The effect of time on the fraction recrystallized $\left(\mathrm{T}=1550^{\circ} \mathrm{C}\right)$ as measured by nanoindentation and EBSD. Comparison with softening fraction $X_{H}$ computed using the mean hardness value.

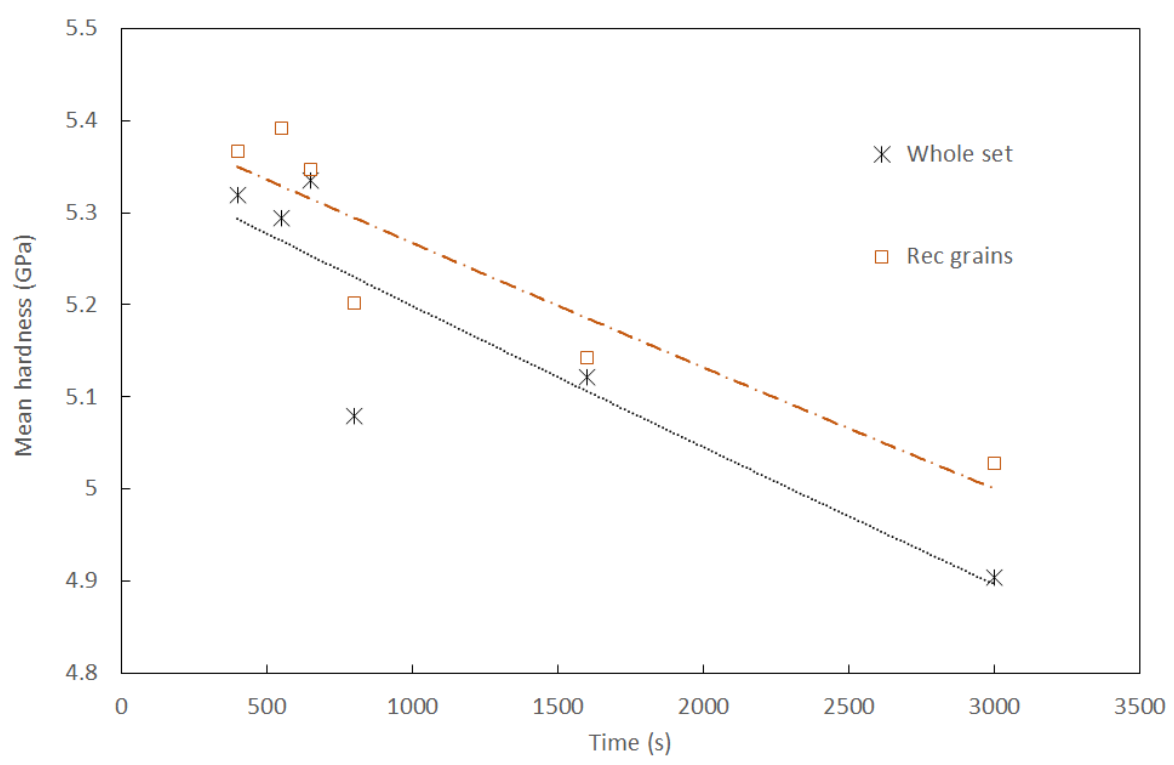

Figure 8. Mean hardness versus time for the whole set of grains or restricted to the recovered grains.

The recovery-induced softening is characteristic of a logarithmic decrease of hardness with time that can be approached with a linear function of time [30], as shown in Figure 8. It is consistent with the Kuhlmann's theory of recovery [3]. A simpler theory is chosen here to model the recovery mechanism. Recovery is intrinsically linked to dislocations rearrangement and annihilation that may occur through various rate-controlling mechanisms, such as dislocation climb, thermally activated glide or cross-slip [3]. There are various ways to describe recovery kinetics through the evolution of dislocation density. Let us consider the following one:

$$
\frac{d \rho}{d t}=-r \rho \rightarrow \rho=\rho_{d} \exp (-r t)
$$


whereby $r$ is a temperature-dependent parameter and $\rho_{d}$ is the initial dislocation density. The nanoindentation hardness is somehow related to dislocation density through the materials yield stress $\sigma$. The famous Tabor relation [31] yields:

$$
H=3 \sigma
$$

The Taylor relation links the yield stress to the dislocation density [32] through Equation (9).

$$
\sigma=\sigma_{r x}+M \alpha \mu b \sqrt{\rho}
$$

whereby $\sigma_{r x}$ is the yield stress of the fully recrystallized materials. Parameters $\alpha$ and $\mathrm{M}$ are dimensionless. In the case of tungsten, the product $M \times \alpha$ is close to 1 . Shear modulus $\mu$ is taken as $160 \mathrm{GPa}$; the burgers vector is $274 \mathrm{pm}$ [33]. The dislocation density can thus be written as a function of the nanohardness.

$$
\rho=\left(\frac{H-H_{r x}}{3 M \alpha \mu b}\right)^{2}
$$

whereby $H_{r x}=3 \sigma_{r x}$ is the hardness of the fully recrystallized materials. The decrease of dislocation density — computed through Equation (10)—versus time is plotted in Figure 9. For each temperature, the variation is consistent with the exponential shape proposed in Equation (7). It is worth noting that such an evolution is also consistent with a recovery mechanism controlled by dislocation climb that would lead to $\frac{1}{\rho}-\frac{1}{\rho_{d}}=r t$ [3].

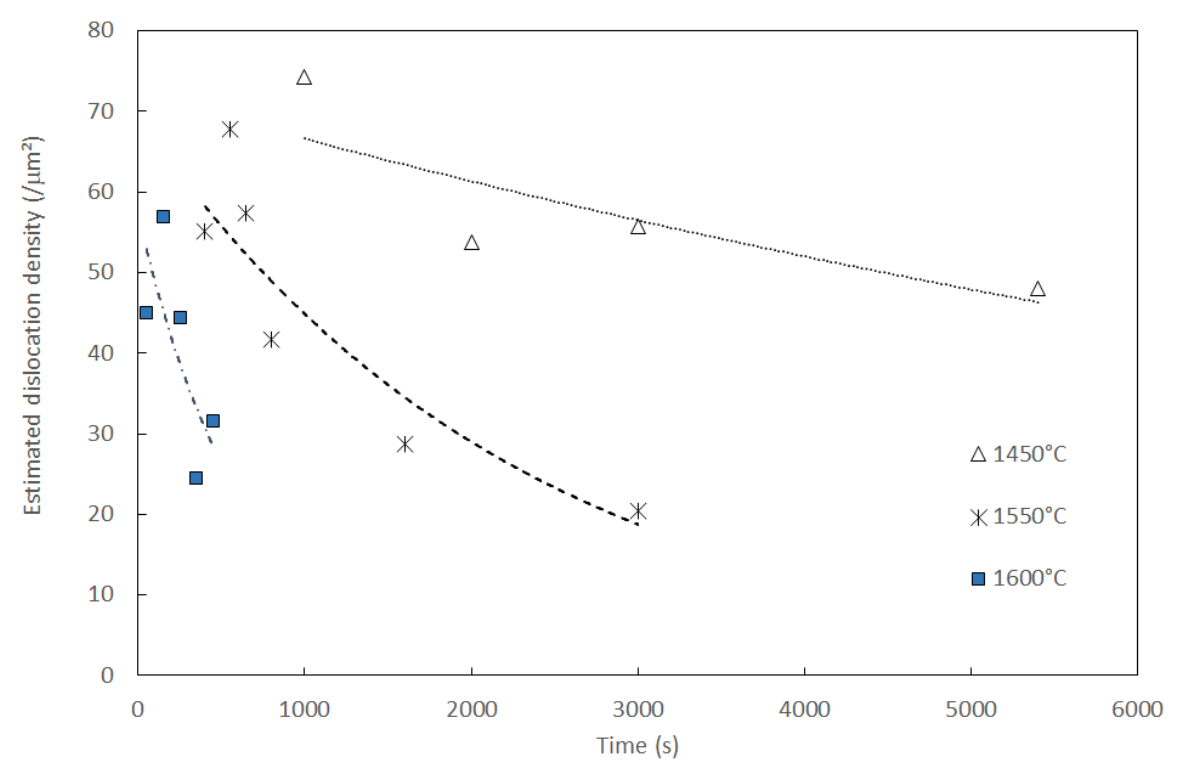

Figure 9. Estimated dislocation density computed from mean hardness versus time at different annealing temperatures.

The recovery coefficient, as defined in Equation (7), is plotted in Figure 10 for temperature range $1450-1600{ }^{\circ} \mathrm{C}$. The recovery parameter increases with temperature, as expected. From this plot and the Arrhenius equation $r=r_{0} \exp \left(\frac{-Q}{\mathrm{R} T}\right)-$ where $Q$ is the activation energy and $\mathrm{R}$ is the universal gas constant-it is possible to extract the related activation energy. It is observed to be about $430 \mathrm{~kJ} / \mathrm{mol}$, which is roughly consistent with the order of magnitude of bulk self-diffusion in tungsten $\approx 500-650 \mathrm{~kJ} / \mathrm{mol}$ [34]. Considering a mechanism controlled by dislocation climb [3], the activation energy would be $\approx 600 \mathrm{~kJ} / \mathrm{mol}$, which is again in agreement with bulk self diffusion. Moreover, some other recovery mechanisms deserve to be explored through this kind of measurement, such as subgrain coarsening. In that case, hardness might be related to the sub-grain size and boundary misorientation $[17,21]$. There is clearly a need for future works in that area. Let us note 
that the recrystallization activation energy might have been evaluated through the time at $50 \%$ recrystallization. Unfortunately, such an investigation was not possible in the present study, since most of the specimens were less than half-recrystallized. It is worth noting that the present paper is a first attempt in the estimation of parameters related to recovery/recrystallization mechanisms through statistical nanoindentation. Despite the observed scatter, the results are roughly consistent with literature.

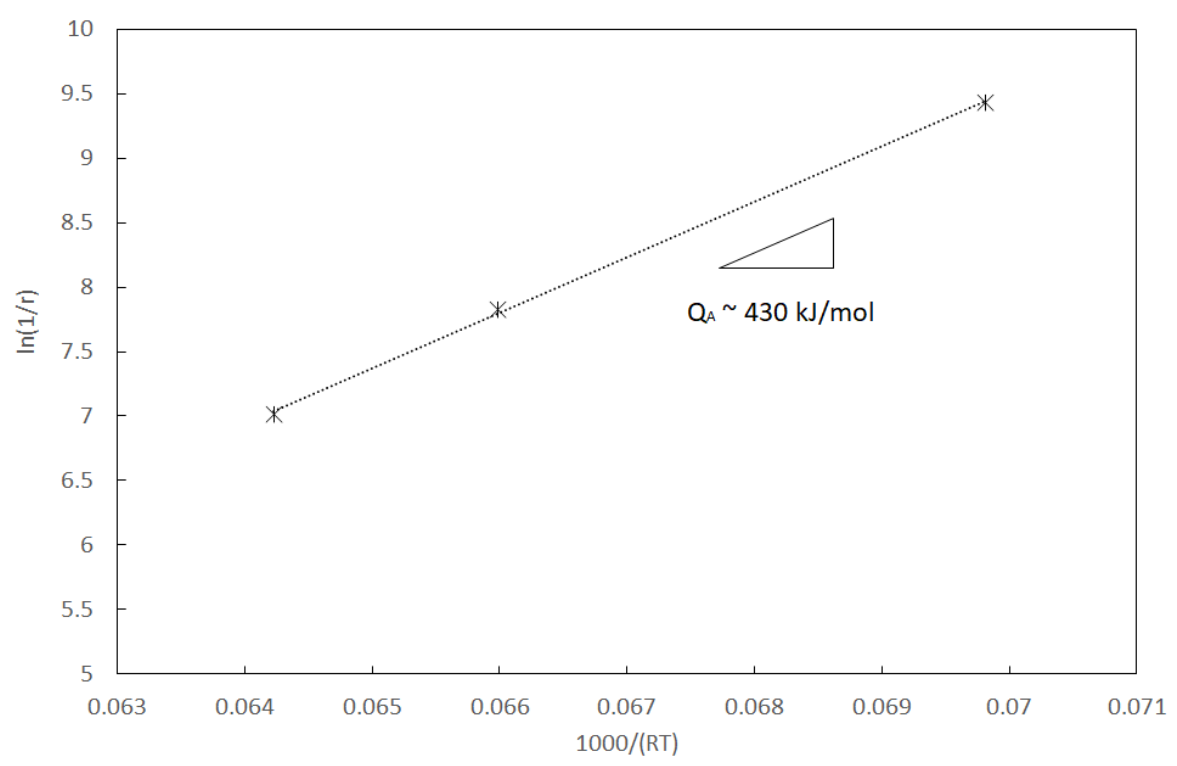

Figure 10. Arrhenius plots of the recovery parameter $r$.

Although statistical nanoindentation analysis seems to be an interesting tool to measure the fraction recrystallized, some intrinsic limitations have to be mentioned. The first one is that the overlap between the hardness distribution of the recovered matrix and that of the recrystallized grains has to remain limited. Otherwise, the recrystallization fraction might be overestimated. Hence, the estimation of the recrystallization fraction using this methodology has to be taken with caution when the overlap exceeds a given threshold. The second limitation is related to the use of statistics themselves. The application of statistical nanoindentation theory [16] requires indentation depth to be smaller than the heterogeneity characteristic size. In a composite materials, this assumption can be checked a priori. In a material undergoing both recovery and recrystallization, the characteristic size is quite difficult to define a priori. For instance, the indentation depth used in the present work was about $1.5 \mu \mathrm{m}$, which corresponds to a $15 \mu \mathrm{m}$ characteristic size. Grains with a smaller characteristic size may be missed. The best way to overcome this issue could be to perform nanoindentation tests with a smaller indentation depth. The latter has to be defined according to the characteristic size of a recrystallized grain, for instance. Nevertheless, given the average grain size, one would require a large number of nanoindentation tests to perform the statistical analysis. It might be of interest to develop a two-scale strategy to focus on regions of interest. It is worth noting that recent advances in ultrafast nanoindentation mapping clear the way for such a development [35]. Further investigations beyond the scope of this paper deserve to be done to extend the set of data. A relation to a initial microstructural state such as texture [36] might be fruitful. Correlating EBSD and grid nanoindentation [24] could be a promising way to better understand the prior deformed state and the measured recrystallization/recovery kinetics. Statistical nanoindentation theory might be useful to compare the effect of various manufacturing processes, the hardness being an indirect signature of the stored energy. 


\section{Conclusions}

This paper presents a first attempt at the use of statistical nanoindentation to measure primary recrystallization and recovery mechanisms in metals. The methodology was applied on ITER-like rolled tungsten samples of commercial purity annealed at elevated temperatures using the laser-annealing set-up presented in the paper of Minissale et al. [7]. Although the results are rather qualitative than quantitative, some conclusions can be drawn:

- The statistical nanoindentation analysis can help to separate contributions of recovery/recrystallization mechanisms to macroscopic softening;

- Recovery/recrystallization mechanisms can be investigated even when they overlap;

- The restoration-induced softening fraction estimated from hardness measurements is always higher than the fraction recrystallized estimated from statistical nanoindentation analysis or EBSD measurements;

- The nanoindentation hardness standard deviation is maximal when the softening fraction approaches $50 \%$ and is minimal both for the initial state and for the fully recrystallized state;

- The statistical nanoindentation analysis is a complementary approach to EBSD measurements to investigate the effect of deformed structure upon the competition between thermally activated restoration processes, such as recovery/recrystallization mechanisms.

Author Contributions: Conceptualization, D.P. and G.K.; methodology, M.L. and G.K.; validation, M.L. and G.K.; investigation, L.K., M.L., A.D., M.M., L.G. and G.K.; resources, M.R., L.G. and G.K.; data curation, L.K. and G.K.; writing-original draft preparation, L.K., M.L. and G.K.; writing-review and editing, A.D., D.P., C.M. and G.K.; visualization, G.K.; supervision, G.K.; project administration, G.K.; funding acquisition, G.K., M.R. and L.G. All authors have read and agreed to the published version of the manuscript.

Funding: This research was funded by FR-FCM-Federation de Recherche sur la Fusion par Confinement Magnétique. This project was partly supported by Andra under the Investments for the Future Program.

Acknowledgments: The authors deeply acknowledge Marilyne Mondon and Gilles Blanc from Mines Saint-Etienne for their help in sample preparation.

Conflicts of Interest: The authors declare no conflict of interest The funders had no role in the design of the study, in the collection, analyses, or interpretation of data, in the writing of the manuscript, and in the decision to publish the results.

\section{References}

1. Hirai, T.; Panayotis, S.; Barabash, V.; Amzallag, C.; Escourbiac, F.; Durocher, A.; Merola, M.; Linke, J.; Loewenhoff, T.; Pintsuk, G.; et al. Use of tungsten material for the ITER divertor. Nucl. Mater. Energy 2016, 9, 616-622. [CrossRef]

2. Durif, A.; Richou, M.; Kermouche, G.; Lenci, M.; Bergheau, J. Impact of tungsten recrystallization on ITER-like components for lifetime estimation. Fusion Eng. Des. 2019, 138, 247-253. [CrossRef]

3. Humphreys, F.J.; Hatherly, M. Recrystallization and Related Annealing Phenomena; Elsevier: Amsterdam, The Netherlands, 2012.

4. Pintsuk, G.; Antusch, S.; Weingaertner, T.; Wirtz, M. Recrystallization and composition dependent thermal fatigue response of different tungsten grades. Int. J. Refract. Met. Hard Mater. 2018, 72, 97-103. [CrossRef]

5. Wirtz, M.; Linke, J.; Loewenhoff, T.; Pintsuk, G.; Uytdenhouwen, I. Transient heat load challenges for plasma-facing materials during long-term operation. Nucl. Mater. Energy 2017, 12, 148-155. [CrossRef]

6. Richou, M.; Durif, A.; Lenci, M.; Mondon, M.; Minissale, M.; Gallais, L.; Kermouche, G.; De Temmerman, G. Recrystallization at high temperature of two tungsten materials complying with the ITER specifications. J. Nucl. Mater. 2020, 542, 152418. [CrossRef]

7. Minissale, M.; Durif, A.; Hiret, P.; Vidal, T.; Faucheux, J.; Lenci, M.; Mondon, M.; Kermouche, G.; Pontillon, Y.; Grisolia, C.; et al. A high power laser facility to conduct annealing tests at high temperature. Rev. Sci. Instrum. 2020, 91, 035102. [CrossRef]

8. Tarasiuk, J.; Gerber, P.; Bacroix, B. Estimation of recrystallized volume fraction from EBSD data. Acta Mater. 2002, 50, 1467-1477. [CrossRef]

9. Moussa, C.; Bernacki, M.; Besnard, R.; Bozzolo, N. About quantitative EBSD analysis of deformation and recovery substructures in pure Tantalum. In IOP Conference Series: Materials Science and Engineering; IOP Publishing: Bristol, UK, 2015; Volume 89, p. 012038. 
10. Bozzolo, N.; Jacomet, S.; Logé, R.E. Fast in-situ annealing stage coupled with EBSD: A suitable tool to observe quick recrystallization mechanisms. Mater. Charact. 2012, 70, 28-32. [CrossRef]

11. Lopez-Sanchez, M.A.; Tommasi, A.; Barou, F.; Quey, R. Dislocation-driven recrystallization in AZ31B magnesium alloy imaged by quasi-in situ EBSD in annealing experiments. Mater. Charact. 2020, 165, 110382. [CrossRef]

12. Oliver, W.C.; Pharr, G.M. An improved technique for determining hardness and elastic modulus using load and displacement sensing indentation experiments. J. Mater. Res. 1992, 7, 1564-1583. [CrossRef]

13. Guillonneau, G.; Kermouche, G.; Bec, S.; Loubet, J.L. A simple method to minimize displacement measurement uncertainties using dynamic nanoindentation testing. Tribol. Int. 2014, 70, 190-198. [CrossRef]

14. Zayachuk, Y.; Armstrong, D.; Bystrov, K.; Van Boxel, S.; Morgan, T.; Roberts, S. Nanoindentation study of the combined effects of crystallography, heat treatment and exposure to high-flux deuterium plasma in tungsten. J. Nucl. Mater. 2017, 486, 183-190. [CrossRef]

15. Constantinides, G.; Chandran, K.R.; Ulm, F.J.; Van Vliet, K. Grid indentation analysis of composite microstructure and mechanics: Principles and validation. Mater. Sci. Eng. A 2006, 430, 189-202. [CrossRef]

16. Randall, N.X.; Vandamme, M.; Ulm, F.J. Nanoindentation analysis as a two-dimensional tool for mapping the mechanical properties of complex surfaces. J. Mater. Res. 2009, 24, 679-690. [CrossRef]

17. Nes, E. Recovery revisited. Acta Metall. Mater. 1995, 43, 2189-2207. [CrossRef]

18. Verdier, M.; Brechet, Y.; Guyot, P. Recovery of AlMg alloys: Flow stress and strain-hardening properties. Acta Mater. 1998, 47, 127-134. [CrossRef]

19. Friedel, J. Dislocations: International Series of Monographs on Solid State Physics; Elsevier: Amsterdam, The Netherlands, 2013; Volume 3.

20. Ciucani, U.M.; Thum, A.; Devos, C.; Pantleon, W. Recovery and recrystallization kinetics of differently rolled, thin tungsten plates in the temperature range from $1325^{\circ} \mathrm{C}$ to $1400{ }^{\circ} \mathrm{C}$. Nucl. Mater. Energy 2019, 20, 100701. [CrossRef]

21. Vandermeer, R.; Hansen, N. Recovery kinetics of nanostructured aluminum: Model and experiment. Acta Mater. 2008, 56, 5719-5727. [CrossRef]

22. Cheng, Y.T.; Cheng, C.M. Scaling, dimensional analysis, and indentation measurements. Mater. Sci. Eng. R Rep. 2004, 44, 91-149. [CrossRef]

23. Kermouche, G.; Loubet, J.L.; Bergheau, J.M. An approximate solution to the problem of cone or wedge indentation of elastoplastic solids. C. R. Méc. 2005, 333, 389-395. [CrossRef]

24. Sanchez-Camargo, C.M.; Hor, A.; Salem, M.; Mabru, C. A robust method for mechanical characterization of heterogeneous materials by nanoindentation grid analysis. Mater. Des. 2020, 194, 108908. [CrossRef]

25. Nix, W.D.; Gao, H. Indentation size effects in crystalline materials: A law for strain gradient plasticity. J. Mech. Phys. Solids 1998, 46, 411-425. [CrossRef]

26. Bachmann, F.; Hielscher, R.; Schaeben, H. Grain detection from 2d and 3d EBSD data-Specification of the MTEX algorithm. Ultramicroscopy 2011, 111, 1720-1733. [CrossRef] [PubMed]

27. Hadadzadeh, A.; Mokdad, F.; Wells, M.; Chen, D. A new grain orientation spread approach to analyze the dynamic recrystallization behavior of a cast-homogenized $\mathrm{Mg}-\mathrm{Zn}-\mathrm{Zr}$ alloy using electron backscattered diffraction. Mater. Sci. Eng. A 2018, 709, 285-289. [CrossRef]

28. Ayad, A.; Ramoul, M.; Rollett, A.; Wagner, F. Quantifying primary recrystallization from EBSD maps of partially recrystallized states of an IF steel. Mater. Charact. 2020, 110773. [CrossRef]

29. Baral, P.; Laurent-Brocq, M.; Guillonneau, G.; Bergheau, J.M.; Loubet, J.L.; Kermouche, G. In situ characterization of AA1050 recrystallization kinetics using high temperature nanoindentation testing. Mater. Des. 2018, 152, 22-29. [CrossRef]

30. Alfonso, A.; Jensen, D.J.; Luo, G.N.; Pantleon, W. Thermal stability of a highly-deformed warm-rolled tungsten plate in the temperature range $1100-1250{ }^{\circ} \mathrm{C}$. Fusion Eng. Des. 2015, 98, 1924-1928. [CrossRef]

31. Tabor, D. The Hardness of Metals; Oxford University Press: Oxford, UK, 2000.

32. Cottrell, A. Theory of dislocations. Prog. Met. Phys. 1949, 1, 77-126. [CrossRef]

33. Wei, Q.; Kecskes, L. Effect of low-temperature rolling on the tensile behavior of commercially pure tungsten. Mater. Sci. Eng. A 2008, 491, 62-69. [CrossRef]

34. Lassner, E.; Schubert, W.D. Properties, Chemistry, Technology of the Element, Alloys, and Chemical Compounds; Kluwer: Vienna, Austria, 1999.

35. Hintsala, E.D.; Hangen, U.; Stauffer, D.D. High-throughput nanoindentation for statistical and spatial property determination. JOM 2018, 70, 494-503. [CrossRef]

36. Raabe, D.; Roters, F.; Marx, V. Experimental investigation and numerical simulation of the correlation of recovery and texture in bcc metals and alloys. Texture Stress Microstruct. 1996, 26, 611-635. [CrossRef] 